Massachusetts, for his outstanding contributions towards the development of synthetic polarizers for light (for example, 'Polaroid') ; of stereoscopic photography using polarized light one-step photography ('Land' camera); of the ultra-violet colour-translation microscope; and of the use of plastics and colloids in optics. Honorary Fellowship of the Royal Photographic Society has been conferred upon Dr. John I. Crabtree (Research Laboratories, Eastman Kodak Co.), who has been responsible for major developments in the practice of processing black-andwhite still- and motion-pictures; and also upon Dr. E. H. Land.

\section{Pooling Scientific Resources in the Western World}

IN a written answer given on January 21 in the House of Commons to a question regarding the Government's policy as to the pooling of scientific knowledge in the interests of international peace and co-operation, Mr. R. A. Butler re-affirmed that the Government is in favour of pooling scientific resources. He added that discussions with other members of the North Atlantic Treaty Organization and the Organization for European Economic Co-operation are procesding with the view of promoting this continuing co-operation. The most important recent step towards scientific co-operation in the government field has been the joint decision of the North Atlantic Treaty Organization to establish a Science Committee and to appoint a Science Adviser to the Secretary-General.

\section{Technical and Technological Education in Scotland}

ReplyiNG on January 21 to a question in the House of Commons regarding the expansion of scientific and technological education in Scotland, the Joint Under-Secretary of State for Scotland, Mr. N. Macpherson, said that projects to the value of $\mathfrak{£ 7 , 3 0 0 , 0 0 0}$ have already been approved by the Secretary of State. He added that further projects to the value of $£ 1,200,000$ are being considered and it is expected to receive shortly a scheme for the remaining $£ 1,500,000$. Every opportunity is being taken by means of conferences and other forms of publicity to encourage employers and young workers to make full use of the facilities available.

\section{National Science Foundation Grants for Research Reactors}

Two major grants for research reactors are to be made by the National Science Foundation, namely, a 300,000 dollar grant to the State College of Washington, at Pullman; and a 150,000 dollar grant to the University of Virginia, at Charlottesville. The reactor facility to be constructed at the State College of Washington will be a swimming-pool type, heterogeneous resctor using enriched fuel elements and moderated by water. The reactor will have twelve beam ports, a thermal column, and at a power level of $100 \mathrm{~kW}$. will provide a core flux of about $10^{12}$ neutrons $/ \mathrm{cm} .{ }^{2} / \mathrm{sec}$. The project is under the direction of Harold W. Dodgen, of the Department of Chemistry. The proposed facility is near seven other institutions of higher learning and is expected to contribute to the development of a regional programme in reactor research and training in nuclear technology. The project is also being assisted by the U.S. Atomic Energy Commission. The research reactor at the University of Virginia will also be of a swimming-pool type. The School of
Enginering is participating in the design and construction of the reactor, thereby making possible appreciable savings in cost. The project is under the direction of Lawrence R. Quarles, dean of the School of Engineering. The staff has been actively planning research with nuclear radiation in the fields of biology, chemistry, engineering, medicine and physics. Nuclear fuel for both reactors will be provided by the United States Atomic Energy Commission.

The Midwestern Universities Research Association

TuE National Science Foundation has awarded a grant of 160,000 dollars to the Midwestern Universities Research Association, Madison, Wisconsin, for the support of basic research entitled "High Energy Accelerator Studies". The research is under the direction of Keith R. Symon, of the University of Wisconsin. Since 1953, scientists of the Association have been investigating methods of accelerating particles to energies of billions of electron volts. They discovered that a machine based on the principle of a fixed-field-alternating gradient was feasible, and a model was built to demonstrate this principle. The basic theory of accelerators was also developed to a point in advance of anything that had thus far been achieved. The work was facilitated by the use of high-speed computing machines, which were used to carry out analyses not otherwise possible. With the new grant, which supplements funds received from the U.S. Atomic Energy Commission, the Midwestern Universities Research Association expects to continue those studies of new weys of producing high-energy collisions involving beams of protons. It will continue to investigate the orbits and accelerating field configurations for the intersecting-beam method of producing 'effective' energies of tens of billions of electron volts. Theoretical studies will be made of the temporary 'stacking' of orbiting particles. Because the feasibility of an intersecting-beam accelerator depends on the intensity in the beam, it is planned to build a new pilot model to test the theoretical calculations that have been made on beam intensity. The model will operate at 50 million $\mathrm{eV}$. and be so built that counter-circulating beams of particles can be studied. The radiation effects and the spurious interaction of these circulating beams will also be investigated.

\section{History of Libraries}

IN his inaugural lecture, "The Golden Chain : a Study in the History of Libraries", at University College, London, on November 21, Prof. R. Irwin suggested that the history of libraries is essentially concerned with the conquest of space and time by the art of recording communications, and involves not only the history of scholarship in its narrower sense, but also of human civilization, culture and literacy. Moreover, he pointed out that the genealogy of scholarship and letters is as complex as any family tree. Books have their ancestry and descendants, and $a$ book is a kind of reincarnation of the author that gradually gathers to itself an independent life of its own. An author's literary offspring are always the result of a marriage between his own mind and the communicated experience of other minds, in the main received through the medium of books, so that the conception and birth of the new book commonly occurs in the author's library or, for a scientist, in his laboratory. Prof. Irwin suggested that a library can be defined as a community in which reader and writer meet, to which both contribute something of 